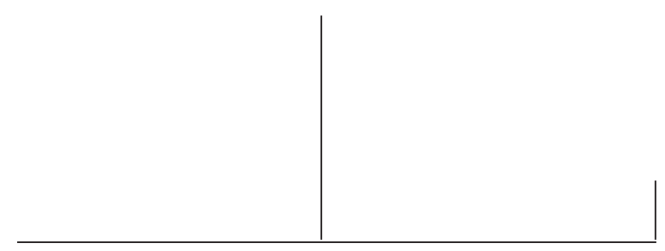

Rev. Latinoam. Psicopat. Fund., IV, 4, 103-111

\title{
Fingimientos identificatorios psicóticos con el padre durante la adolescencia
}

\author{
José de Jesús Gonzáles Núñez \\ Vanessa Nahoul Serio
}

\begin{abstract}
En el adolescente psicótico hay una alteración de la identidad y pueden presentarse delirios de filiación, delirios referidos a la identidad sexual o un alejamiento de la realidad sin delirio aparente. Los fingimientos identificatorios en el adolescente pueden ser introyectos distorsionados, no predecibles $y$ abundantes del padre. Estos síntomas psicóticos, la fragmentación y el aniquilamiento, pueden ser a su vez defensas contra la ansiedad. Se presenta el caso de Javier Fernando, en tratamiento psicoanalítico, en el cual éste debe reconocer y realizar la alianza con su monstruo, que es un introyecto deformado e igualmente el terapeuta tiene que realizar la alianza con el monstruo.
\end{abstract}

Palabras clave: Adolescente psicótico, identidad, delirios, identificación 


\section{Psicosis en la adolescencia}

La psicosis se origina por un conflicto entre el yo y la realidad; la neurosis, por el conflicto entre el yo y el ello. Dos pasos forman la psicosis: 1) ocurre una rebelión contra la realidad, negándola, y 2) en vez de compensar el daño hecho a la realidad, el yo crea un mundo interno y externo nuevos, y es guiado por las pulsiones y lo reprimido. Antes de la disociación del mundo externo hubo una frustración intolerable de un deseo inconsciente (Thompson, 1994). Es decir que en la psicosis, hay una primera negación seguida por una fase de reconstrucción activa para reemplazar la realidad; mientras que la neurosis no niega la realidad, sólo la ignora.

Las reacciones psicóticas se presentan en adolescentes que cuentan con una historia previa de psicosis infantil (Mayer-Gross et al, citados por Holzman y Grinker, 1974) y que por la ansiedad y estrés en que viven, se desencadenan procesos adictivos diversos: comida, bebida, drogas, masturbación etc. Tienen un grado de labilidad acentuada por situaciones traumáticas o ansiógenas. A ello se agrega el impacto de las transformaciones fisiológicas y psíquicas subsiguientes.

Hacia los 17 años el adolescente se va adaptando a innumerables cambios y tareas nuevas, tales como independizarse, definir un plan de vida, conformar una identidad para su Yo y lograr la capacidad de intimidad. Para el adolescente psicótico, estas tareas son casi imposibles de resolver, por los conflictos intrapsíquicos e intrafamiliares que viven. Las creencias y temores de los padres impiden la ayuda que puedan brindar a su hijo adolescente para que éste logre una buena socialización fuera del círculo familiar. 


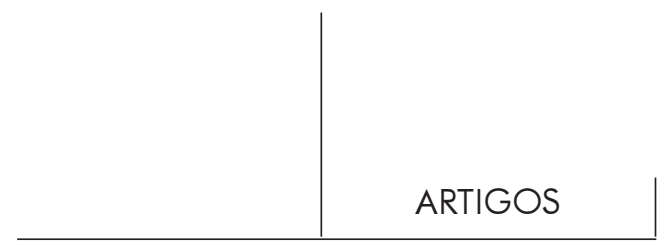

El caso que presentaremos es el de Javier Fernando, un post-adolescente de 17 años cuyo trastorno consiste en un fingimiento identificatorio psicótico con su padre. Javier Fernando se vio llevado a negar la realidad externa para reconstruirse una realidad psicótica fingida mediante alucinaciones auditivas de voces que lo empujaban a seducir indiscriminadamente a hombres o mujeres sin importar edad o posición social. Presentaba síntomas tales como: trastornos de comportamiento, falta de participación afectiva en el diálogo y aparición momentánea de elementos delirantes.

Empezó a escuchar voces acerca de lo que debía y de lo que no debía hacer, trastocando el sentido y la moralidad de sus actos. Así, por ejemplo, veía una mujer y las voces le decían: "Respétala", pero él impulsiva e inconscientemente se acercaba y las tocaba eróticamente, "se las torteaba", como él mismo decía, reportando que lo hacía sin sentir nada, como si no lo hubiera hecho. Las voces incluían la orden de no decirle a nadie que las escuchaba hasta que finalmente en medio de esa fragmentación se involucró homosexualmente y su Yo se fracturó al grado que hubo necesidad de internarlo. Después de cuatro semanas de internamiento y de tratamiento farmacológico, empezó a tener control sobre su conducta motora: forma de caminar, de agarrar las cosas, forma de sostener la mirada, y comenzó a hablar de las voces y a interesarse en continuar su preparatoria.

Amado (1985) explica que el adolescente psicótico no consolida la conciencia de sí mismo y del mundo que le rodea. Se cuestiona la existencia misma de los puntos de referencia indispensables a la vida. Todo está confuso en cuanto a su Yo, su sí mismo, su cuerpo, el cuerpo del otro, está trastocada la alteridad, los objetos, el mundo mismo. Fracasa en la tarea de reconstruirse a través de nuevas identificaciones y siente que pierde coherencia interna. Se rompen los límites entre las representaciones de sí mismo y del objeto dejando una impresión de disonancia y sensaciones de vaguedad.

En Javier Fernando, se encuentran los fingimientos identificatorios que él posee con su padre. Son aspectos parciales del padre, las voces que escucha son voces paternas que tienen un vestigio materno, que tienen un antecedente materno, pero que en realidad, en este momento de la psicosis, son un fingimiento paterno. Igual las miradas, él mira seductoramente como percibe que el padre mira a los hombres y, finalmente, desarrolla un fingimiento identificatorio homosexual como supone que su propio padre lo realiza.

Desde la perspectiva de la hipótesis estructural, el conflicto en las psicosis consiste en que el Yo es invadido por una ansiedad que le impide funcionar con eficiencia y conforme a la realidad externa e interna. El Yo se desarrolla anormalmente por lo que requiere de mecanismos de defensa muy primitivos que deforman la realidad, tales como: la escisión, la idealización primitiva, la identificación proyectiva, la negación, omnipotencia, devaluación etc. Estas defensas lo protegen de la desintegración y de la fusión del sí mismo con el objeto (González Núñez, 1992). La 


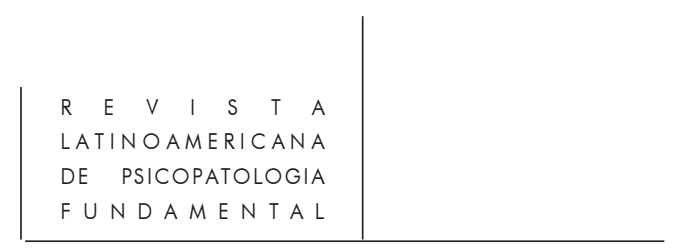

elevada ansiedad lleva al psicótico a sentir la necesidad de proteger a sus objetos de su agresión y la única forma es rompiendo con ellos y apartándose de la realidad. El Superyó juega un papel muy importante, y por su carácter primitivo se torna demandante y castigador con el Yo, la severidad del Superyó puede verse reflejada en alucinaciones auditivas, como las voces que escuchaba Javier Fernando, que lo amenazaban, en caso de delatar que existían, con la descarga impulsiva. Las exigencias hacia el Yo son fuertes, compulsivas y de carácter punitivo, y para satisfacerlas se utiliza la fantasía, llegando en algunos casos a conductas autodestructivas y castigadoras como la automutilación. Las alucinaciones y delirios pueden tener también influencia del Ideal del Yo. Es decir que alrededor de ciertos ideales se estructuran los delirios. Javier Fernando tiene fuertes creencias religiosas que le imponen los ideales de ser hombre y un buen hijo.

La alteración de la estructura yoica puede deberse a factores constitucionales, que no se encontraron en este paciente; o carencias afectivas durante la primera infancia, traumas severos o una relación madre-hijo dañina. Javier Fernando recibió la influencia abrumadora y aplastante de una madre psicótica, y esto también le impidió formar una identidad cohesiva. Además sufría de una gran ansiedad a causa de sus impulsos agresivos, y para preservar a sus objetos de su propia agresión rompió con ellos, retrayéndose del mundo externo.

La pérdida de contacto con la realidad en Javier Fernando se manifestó en el tratamiento como una disminución progresiva de las capacidades cognitivas: percepción, atención, memoria, pensamiento, lenguaje, inteligencia y conducta motora (áreas libres de conflicto del yo). El pronóstico no era favorable por el deterioro de la función intelectual y del lenguaje. En el trascurso de ocho meses en tratamiento de psicoterapia psicoanalítica, presentó conductas de desintegración en las que mostraba una fragmentación de su conducta. Bajó ostensiblemente de calificaciones, mostrando que su inteligencia había sido invadida por el conflicto y aunque no dejaba de ser inteligente, sí disminuyó notablemente su atención y su capacidad de aprender.

La realidad psicótica, reconstruida, fingida, de Javier Fernando, tiene características comunes a otras formas de psicosis adolescente, tales como: 1) busca sustituir la función de juicio de realidad y busca constituirse en un reducto narcisista y omnipotente que preserva la autoestima; 2 ) adquiere autonomía, escindiéndose del resto de la personalidad; 3) se localiza dentro del sí mismo, adherida a éste o fuera de él; 4) dentro del sí mismo invade áreas del pensamiento, aparatos, sistemas, funciones fisiológicas etc. (Dupont, 1988); 5) domina el resto de la personalidad mediante mandatos morales inflexibles, que si son violados despiertan dolor físico o moral, culpa o ansiedad. Su obediencia obsesiva promete bondad, amor y autoestima; 6) adaptativamente, persiguen la tolerancia a la cercanía y la convivencia con objetos temidos. También permiten la realización de tareas originalmente rechazadas o indeseables. 


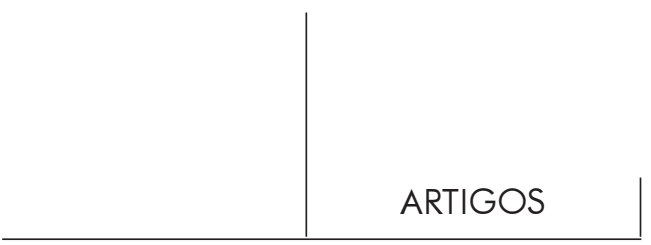

Alteraciones de la identidad en el adolescente psicótico

Las alteraciones ocurren en la relación con la realidad y en los sentimientos de realidad, y la capacidad de prueba de realidad se pierde. En las estructuras psicóticas, hay falta de diferenciación entre las representaciones del sí mismo y de los objetos.

La difusión de la identidad consiste en que los aspectos contradictorios del sí mismo y de los demás no están integrados ni diferenciados o hay una identidad de delirio. En Javier Fernando existe la idea delirante identificatoria con el padre ya que lo introyecta parcialmente y actúa fingidamente como si fuera él, en posiciones físicas: se para igual que el padre, tiene mirada fija, inquisitiva y seductora y da órdenes verbales igual que lo hace el padre.

\section{Delirios en el adolescente psicótico}

Una vez que se han negado fragmentos importantes de la identidad, es indispensable para mantener la vida, la reconstrucción de una neo-realidad a través de una identidad fingida, aparentemente ventajosa para Javier Fernando, aunque aberrante. Cuanto más amenazada se halla de morbilidad la estructura psicótica (Bergeret, 1974/1980), más prevalece en ella el proceso primario sobre el secundario.

El adolescente psicótico puede presentar delirios de filiación (Fenichel, 1973) $\mathrm{y}$ alteraciones en sus relaciones interpersonales, donde sus figuras primitivas le han fallado causándole frustración, por lo tanto, intenta depositar en otra persona, de forma repentina, sus sentimientos; de manera que un desconocido es depositario de todos los afectos tiernos, pero esto es sólo pasajero; posteriormente experimenta una sensación de pérdida, siente al mismo tiempo el deseo y el temor de fundirse en una unión simbólica con el otro; sin embargo quiere ser distinto, quiere tener una identidad propia, pero se siente invadido por el temor de ser abandonado y perder la seguridad que el otro le brinda. Busca la satisfacción inmediata de todas sus necesidades.

\section{Fingimiento identificatorio en el adolescente psicótico}

En los adolescentes psicóticos como Javier Fernando, las fijaciones amorosas, apasionadas e inestables, son identificaciones primitivas, semejantes a las que se establecen en el primer estadio infantil, en donde no hay objeto amoroso (Ekstein, 1966/1969) distinto de las figuras familiares. Por lo cual no existe un cambio interno en el amor ni en las convicciones del individuo, sino más bien una pérdida de personalidad.

Por lo general las figuras paternas de estos pacientes fueron pobres objetos de introyección e identificación por su propia vacuidad, inestabilidad e inconfiabilidad. 


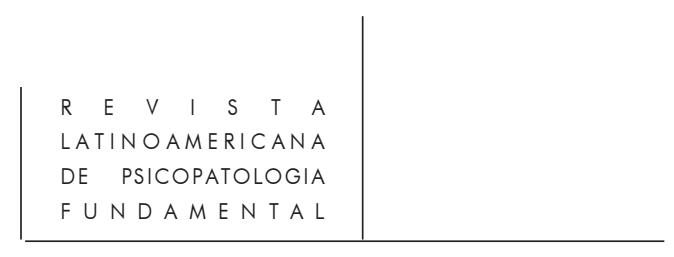

El padre de Javier Fernando parece una contradicción porque siendo una fuente pobre de identificación, la estimulación es muy fuerte. Sin embargo, sus aproximaciones son vacías y carentes del nutrimento afectivo en la relación con su hijo, lo que lo vuelve una figura impredecible ya que finge, igual que el hijo, dar una identidad masculina que no da.

En el desarrollo normal, durante la latencia, las ansiedades derivadas del Superyó presionan al niño a identificarse más con los objetos externos. Si las ansiedades persecutorias son fuertes, mayor será la necesidad de efectuar identificaciones totales con objetos externos (Rosenfeld, 1978). En esta identificación se proyectan aspectos idealizados y persecutorios del Superyó temprano, pero las proyecciones son negadas en apoyo de las cualidades de los objetos externos. Si dichas proyecciones no se niegan, el yo escinde los aspectos persecutorios e idealizados del Superyó temprano, aspectos que reaparecen normalmente en la adolescencia y se proyectan sobre objetos externos; para facilitar la externalización hay una necesidad de negar los aspectos reales de los objetos externos. El Superyo persecutorio, primitivo de Javier Fernando le impide ver a una madre y a un padre integrados, sólo percibe aspectos parciales, persecutorios, que lo angustian, lo ponen agresivo y lo desintegran.

En la génesis del conflicto de Javier Fernando, se encuentra la presencia de una madre psicótica, que le impuso frustraciones intolerables, siendo poco empática y aplastante; imponía su interpretación tanto a los acontecimientos escolares y de relaciones interpersonales de Javier Fernando y no escuchaba la interpretación que el propio hijo hacía. A su padre, un hombre débil, se le dificultaba mucho mantenerse en un trabajo, era muy querulante y saboteador de los logros del hijo. Era además incapaz de cumplir con las funciones de paternidad normales, tales como: ayudar en el control de afectos e impulsos, dar juicio de realidad, prestarse como una figura de identificación psicosexual. De ahí que la identificación con esta figura fuera fingida, en un intento de darle cohesión al yo, de calmar la angustia de fragmentación, de adquirir una identidad y de reconocerse a sí mismo, aspectos que se reajustan intrapsíquicamente en la adolescencia y que al mismo tiempo forman parte de todo proceso psicótico (Marcelli y Braconnier, 1986).

\section{Tratamiento psicoanalítico de los fingimientos identificatorios psicóticos con el padre en la adolescencia}

El trastocamiento en la relación con el padre se vuelve un obstáculo en el aspecto transferencial del tratamiento. Esta limitante se supera de varias maneras: fortaleciendo al Yo, introyectando al terapeuta y considerándolo guía y consejero cuando el paciente se siente ansioso y perplejo. El introyecto del terapeuta en el Superyo, sirve de fundamento para la función de juicio de realidad. Además, el anclaje firme del terapeuta 


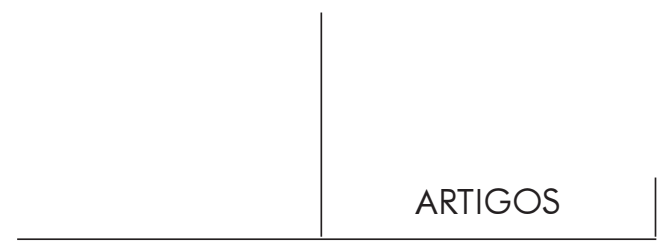

en la actualidad y su certeza de constancia y estabilidad, pueden provocar una respuesta en el paciente aun si su capacidad introyectiva está deteriorada o es incompleta debido a que sus introyectos tempranos fueron evasivos e inconstantes.

Los problemas especiales de transferencia que pueden presentarse durante el tratamiento son en el contacto intermitente que establecen estos pacientes: se conectan pero luego se desconectan abruptamente, perdiéndose la meta y el objetivo y haciéndolos impredecibles y fluctuantes.

El padre de Javier Fernando, cuya identidad masculina era fingida, ya desde antes de casarse, hacía alarde de su masculinidad como una forma de reafirmar esa identidad parcial. Cuenta la madre del paciente que siendo novios, iban en el coche y se detenían para que él exhibiera su pene a los que iban en el otro coche, hombres o mujeres, siendo un exhibicionismo indiscriminado. Entonces, ella no lo percibía como algo inadecuado, era permisiva y se enorgullecía de la supuesta virilidad de su novio. A la vuelta de los años, el padre de Javier Fernando se exhibía en casa de la misma manera frente a sus hijos, mostrándoles "a un verdadero hombre". La madre seguía siendo permisiva ante las provocaciones de su esposo.

El paciente fue introyectando los aspectos parciales que forman el "monstruo" internalizado que ocupó el lugar de lo masculino en su identidad. El monstruo era ese padre seductor, con aspectos homosexuales, y de exhibición indiscriminada.

El desarrollo de la alianza terapéutica permitió que Javier Fernando hablara acerca del monstruo, o sea, de los aspectos homosexuales, suyos y de su padre. En una sesión, mientras hablaba, empezó a tocarse la cara con ambas manos, como si se acariciara, como si se sobara las mejillas. Esto llamó la atención del analista, y notó que Javier Fernando tenía vello en todo el cuerpo a excepción del rostro, el cual era totalmente lampiño. Este era un rasgo de femineidad. El paciente explicó que así, tocándose la cara, él inhibía su crecimiento. Resulta difícil comprobar si esto es cierto o no. Lo que sí muestra es al monstruo introyectado: un monstruo seductor y homosexual, lampiño y afeminado. Más importante aún, en esa sesión el paciente se tocaba el rostro liso, sin vello, tocando una región femenina de su cuerpo, simbolizada en su rostro y en ese tocarse y hablar seducía al terapeuta inconscientemente. Es decir que él estaba actuando en la transferencia como su padre: se exhibía provocativamente frente al padre-analista como tantas veces su padre lo hizo frente a él, que entonces lo observaba pasivamente. Él fue su padre frente al terapeuta, en una identificación fingida, sintiéndose vacío y confundido a causa del fingimiento. El analista, al no responder a su seducción con una conducta provocativa, como su padre, ni con represalias, como su propio Superyó punitivo, ni con indulgencia exagerada, como su madre, ayudó a contener esa homosexualidad y a ir formando una identidad no fingida, que llenara el vacío psicótico de su realidad negada. De esta manera, el analista "exorcizaba" al monstruo de Javier Fernando, a través de su presencia neutral, no sobreestimuladora. 


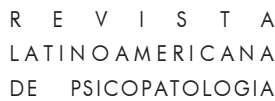

Para unir el funcionamiento psíquico, el analista funciona primero como injerto psicológico que rellena y une el camino entre las islas separadas, desconectadas, fragmentadas y proyectadas (en el caso de los objetos paranoides persecutorios, como las voces) de la estructura psíquica. Al traer al monstruo a la sesión analítica se le compromete en un proceso terapéutico, tratándolo como una ilusión mutua y temporal de la locura de dos, poniendo así un eslabón entre el paciente y el terapeuta. Los monstruos se vuelven además susceptibles a la interpretación que se le hace al paciente. Se muestra además que el monstruo tiene una función positiva a pesar de sus métodos sádicos y crueles y se trata de hacer que éste se vuelva más racional, por medio del diálogo continuo con él, cambiando así la naturaleza misma del monstruo. El paciente desarrolla poco a poco la fuerza y distancia para tratar él mismo, de influenciar a los monstruos para que consigan sus propósitos de manera menos punitiva y destructiva y más adaptativa. Así, integra las partes monstruosas de sí mismo y sus sentimientos hacia el terapeuta.

\section{Referências}

AmAdo, G. Fundamentos de la psicopatología. Barcelona: Gedisa, 1985.

BERGERET, J. (1974). La personalidad normal y patológica. Barcelona: Gedisa, 1980

Dupont, M.A. (1988). La práctica del psicoanálisis. México: Ed. Pax, Librería Carlos Césarman, 1989.

EкSTEIN, R. (1966). La psicosis infantil. México: Pax, 1969.

GonZÁlez Núñez, J. J. Interacción grupal. México: Nociones, Planeta, 1992.

Holzman, P.S. and Grinker, R.R. Schizophrenia. Adolescence. Journal of Youth and Adolescence. New York: Plenum Publishing Corporation, vol. 3, n. 4, p. 267-280, 1974. KeRnBERG, O.F. Trastornos graves de la personalidad. México: Manual Moderno, 1987. Ledoux, M.H. Concepciones psicoanalíticas de la psicosis infantil. México: Paidós, 1987. Marcelli, D. y Braconnier, A. Manual de psicopatología del adolescente. México: Masson, 1986.

Reca, T. Psicoterapia de la psicosis en la adolescencia. Buenos Aires: Paidós, 1979.

Rosenfeld, H.A. Estados psicóticos. Buenos Aires: Horme, 1978.

Thompson, M.G. The Truth about Freud's Technique. New York: New York University Press, 1994.

\section{Resumos}

No adolescente psicótico existe uma alteração da identidade, e delírios de filiação podem estar presentes, delírios referidos à identidade sexual ou um distanciamento da realidade sem delírio aparente. Os fingimentos identificatórios no adolescente podem ser introjeções distorcidas, não predizíveis e abundantes do pai. Estes sintomas 


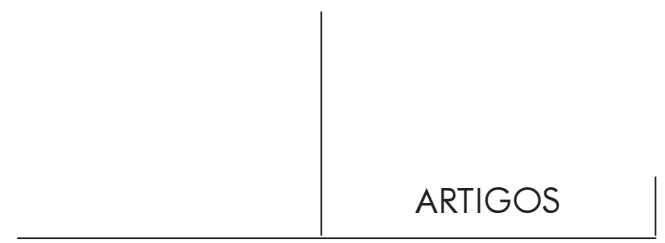

psicóticos, a fragmentação e o aniquilamento podem ser, por sua vez, defesas contra a ansiedade. É apresentado o caso de Javier Fernando, em tratamento psicanalítico, no qual este deve reconhecer e realizar a aliança com seu monstro, que é uma introjeção deformada, e igualmente o terapeuta tem que realizar a aliança com o monstro.

Palavras-chave: Adolescente psicótico, identidade, delírios, identificação

Chez l'adolescent psychotique, on constate une altération de l'identité ainsi que des délires de filiation, des délires qui font allusion à l'identité sexuelle ou bien, un éloignement de la réalité sans aucun délire apparent. Les fausses identifications chez l'adolescent psychotique peuvent être des introjections déformées, pas prévisibles et mombreuses du père. Ces symptômes psychotiques, la fragmentation et l'anéantissement, peuvent être à leur tour des défenses contre l'anxiété. On présente le cas de Javier Fernando qui doit, dans son traitement psychanalytique, reconnaître et réaliser l'alliance avec son monstre qui est une introjection deformée en même temps que le thérapeute est conduit à faire l'alliance avec le monstre.

Mots clés: Adolescent psychotique, identité, délires, identifications

Psychotic adolescents suffer from identity disorders, with the possible presence of delusions regarding paternity or sexual identity, or withdrawal from reality apparently without delusions. Psychotic identificatory pretending regarding the father can be abundant and may be related to unpredictable distorted introjections of the father. The psychotic symptoms of fragmentation and annihilation may also be defenses against anxiety. The case of Javier Fernando is presented. Through his psychotherapeutic treatment this patient was able to recognize and make an alliance with his monster, which is a deformed introjection. In such cases, the therapist must also concurrently enter into an alliance with the monster.

Key words: Psychotic adolescent, identity, delusions, identification

Versão inicial recebida em dezembro de 2000

Versão aprovada em novembro de 2001 